\title{
Spinal Subarachnoid Hemorrhage Caused by a Mycotic Aneurysm of the Radiculomedullary Artery: A Case Report and Review of Literature
}

\author{
Homare Nakamura, ${ }^{1}$ Phyo Kim, ${ }^{1}$ Hideaki Kanaya, ${ }_{1}$ Ryu Kurokawa, ${ }^{1}$ Hidetoshi Murata, ${ }_{1}^{1}$ and Hadzki Matsuda ${ }^{2}$
}

\begin{abstract}
We report a case of spinal subarachnoid hemorrhage $(\mathrm{SAH})$ caused by rupture of a mycotic anerurysm. A 59-year-old woman was admitted to our hospital with a sudden onset of headache and tetraparesis. Computed tomography (CT) scan of the brain revealed $\mathrm{SAH}$, and magnetic resonance imaging (MRI) of the cervical spine showed an acute intradural hematoma. On angiogram, a saccular aneurysm was found on the $\mathrm{C} 5$ radiculomedullary artery, which arose from the left ascending cervical artery. Subsequently, her consciousness status deteriorated due to rebleeding, and she was brought to surgery. An aneurysm was found at the cephalad aspect of the left $\mathrm{C} 5$ root. On histological examination, it showed typical characteristics of mycotic aneurysms. Spinal mycotic aneurysm is a very rare entity with scant description in the literature. It can be extremely brittle and therefore warrants expeditious surgical treatment. When encountering spinal origin of subarachnoid hemorrhage, it should be included in the differential diagnosis.
\end{abstract}

Keywords: spinal cord, hemorrhage, mycotic aneurysms, micro-abscess, arteriovenous malformation

\section{Introduction}

Spinal subarachnoid hemorrhage (SAH) is a rare condition and often takes place in the presence of spinal arteriovenous malformations (AVMs). ${ }^{1-13}$ Spinal SAH has been reported in $6 \%$ of cases harboring AVM, and 75-90\% of the AVM causing SAH are accompanied by aneurysms. ${ }^{2,4,14)}$ Although solitary aneurysms are less common to occur in the spinal vasculature than those accompanying AVMs, several conditions predispose to the generation of aneurysms. The underlying pathology includes dissection, coarctation of the aorta, neoplasm, systemic lupus erythematosus, Behçet's disease, Moyamoya disease, pseudoxanthoma elasticum, and fibromuscular hyperplesia. ${ }^{1,3,6,10,15-21)}$ We report a rare case of spinal SAH associated with mycotic aneurysm.

\section{Case Report}

In February 2006, a 59-year-old female suffered a sudden onset of headache and tetraparesis. When transported to our hospital, she was alert, afebrile, and vital signs were stable. Neurological examination showed upper and lower extremity

Departments of Neurologic Surgery ${ }^{1}$ and Pathology, ${ }^{2}$ Dokkyo University Hospital, Mibu, Tochighi

Received: August 12, 2014; Accepted: November 20, 2014 weakness which was more dense on the right side. She was complaining of hypesthesia on the lower extremities. Deep tendon reflexes were diminished in the upper limbs and brisk in the lower limbs. Past medical history included leg vein varices for which she had been taking antiplatelets. There was no history of trauma. Routine laboratory analysis including coagulation profile revealed no abnormality. Bleeding time was normal. There was no hemorrhagic tendency. Computed tomographic (CT) scan of the head showed SAH predominantly in the posterior fossa. Magnetic resonance imaging (MRI) of the cervical spine revealed an intradural hematoma on the dorsal aspect of the cord (Fig. 1). Angiography was performed. Aortography was unremarkable. Cerebral studies including the posterior circulation was negative for aneurysms. Selective injection into the thyrocervical trunk revealed a small aneurysm at the C5 level arising from the left ascending cervical artery branching off from the trunk (Fig. 2). The neurological findings improved slightly during the imaging studies. On the next day, her level of consciousness deteriorated suddenly. Glasgow Coma Scale (GCS) was 6 (eye opening 1, verbal response 1, best motor responses 4). She was intubated and started on mechanical ventilation. CT scan of the head revealed an increase of the SAH compared to the study taken on the previous day. MRI $\mathrm{T}_{2}$-weighted image of the cervical spine revealed a hyperintense signal in the spinal cord (Fig. 3). Decision was made to extirpate the small aneurysm and to remove the hematoma emergently.

\section{Operation}

C2 to C6 myoarachitectonic spinolaminoplasty was performed in a prone position. ${ }^{22)}$ The dural tube was tensely expanded and discolored with hematoma. A thin membrane consistent with an arachnoid membrane was immediately found after opening the dura. The clot was thicker on the left side, and the spinal cord was compressed. Following meticulous removal of the clot, the aneurysm was identified at the cephalad aspect of the left C5 root (Fig. 4). SAH was most dense around the aneurysm, substantiating that the aneurysm was the source of the bleeding. The neck of the aneurysm was obliterated and coagulated. The dome was resected and sent for histological examination.

After the hematoma was removed, the dura was closed in a watertight fashion. Pulsation of the dural tube was recovered by the end of the operation. The laminae and the spinous processes of $\mathrm{C} 2$ to $\mathrm{C} 6$ were reconstructed using hydroxyapatite implants. ${ }^{22)}$ Her neurological status did not improve after 

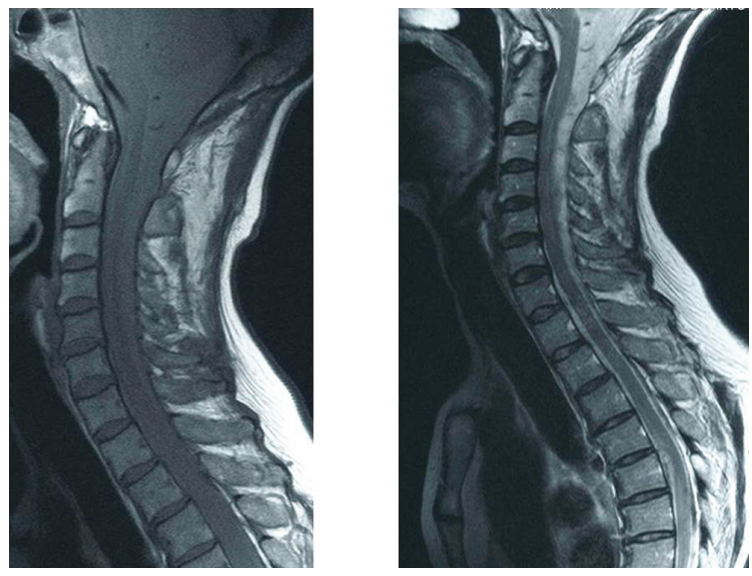

Fig. 1 The spinal hematoma extending from the posterior fossa to $\mathrm{C} 7$, $\mathrm{T}_{1}$-weighted images $\left(\mathrm{T}_{1} \mathrm{WI}\right)$ of magnetic resonance (left) demonstrated an iso-intense signal mass located predominantly posterior to the cord. On $\mathrm{T}_{2}$-weighted images (right), the lesion was a hyper-intense signal compared to the spinal cord. The subarachnoid space is obliterated.



Fig. 2 Selective spinal angiogram showing the saccular aneurysm (arrow) on the left $\mathrm{C} 5$ radiculomedullary artery, a branch of the ascending cervical artery. The staining remained into the late venous phase. surgery, and the patient died 3 days later. Autopsy was not obtained.

\section{Histological findings}

Pathological examination of the resected aneurysm showed partially defective dome as a result of the rupture. ElasticaMasson staining demonstrated that the internal elastic lamina was disrupted. On hematoxylin and eosin (HE) stains, inflammatory cell infiltration, mainly by neutrophils, was prominent in the extensively destroyed aneurysmal wall, with notable micro abscesses (Fig. 5). Gram stain of the specimen was negative. The findings were compatible with a diagnosis of mycotic aneurysm.

\section{Discussion}

SAH of a spinal origin is a rare clinical condition..$^{1-3,69,10,12,14)}$ The most common cause of spinal SAH is an AVM. ${ }^{1-13)}$ Incidence of accompanying aneurysms in the presence of spinal AVMs is reported to be $2.2-7.7 \%$, and possibility of
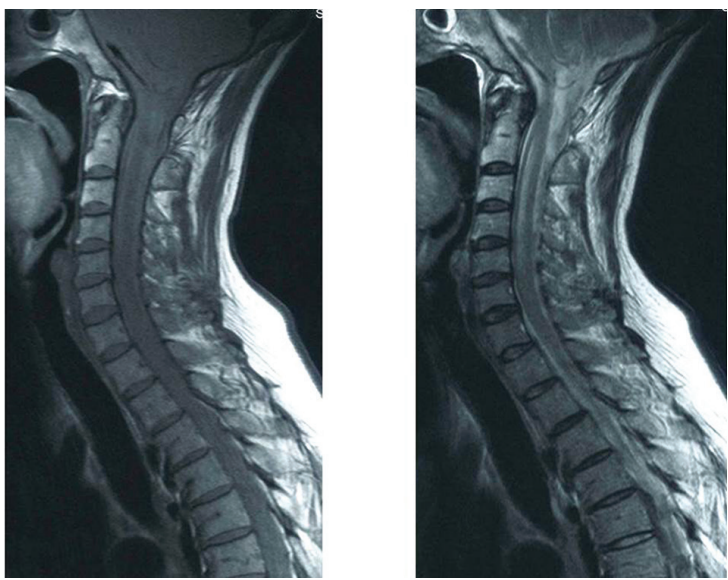

Fig. 3 Magnetic resonance imaging after rebleeding. On $\mathrm{T}_{2}$-weighted image, the hematoma is visualized as a mixed hypo- and hyper-intense signal. Hyper-intense signal is detected inside the spinal cord from C2 to $\mathrm{C} 5$, presumably representing an ischemic change.

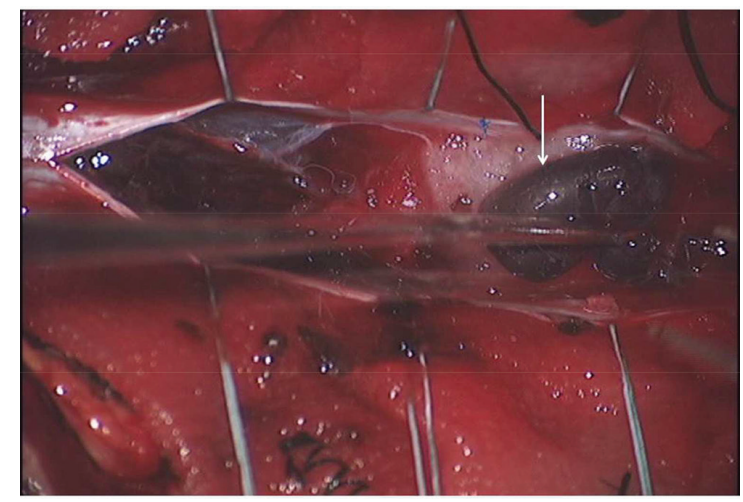

Fig. 4 Intraoperative photograph showing the aneurysm (arrow) retrieved from the cephalad aspect of the left C5 root.

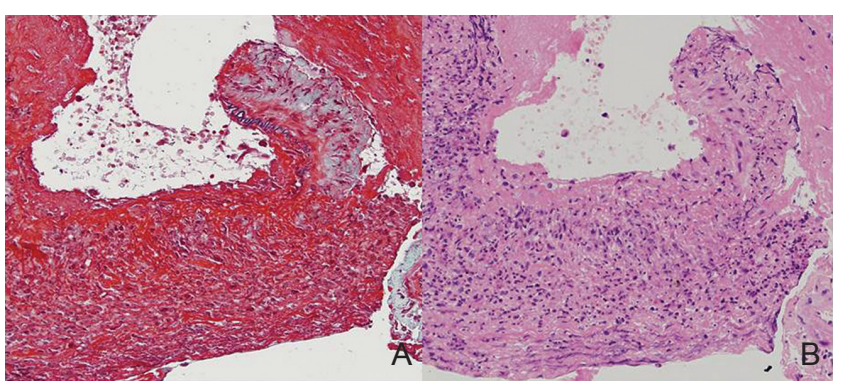

Fig. 5 Photomicrographs of the resected aneurysmal wall. A: The section showing disruption of the internal elastic layer. ElasticaMasson stains, $\times 200$. B: Infiltration of the inflammatory cells is evident. Hematoxylin-Eosin stains, $\times 200$.

aneurysmal rupture has to be taken into consideration. ${ }^{7,23)}$ Other conditions known to be associated with solitary spinal aneurysm include dissection of the aorta, coarctation of the aorta, neoplastic lesion, systemic lupus erythematosus, Behçet's disease, Moyamoya disease, pseudoxanthoma 
Table 1 Summary of all reported cases of subarachnoid hemorrhage caused by solitary spinal aneurysm (not accompanying arteriovenous malformations)

\begin{tabular}{|c|c|c|c|c|c|c|c|c|c|}
\hline Case no. & Author & Age & Sex & Etiology & Level & Operation & Pathology & Deterioration & Outcome \\
\hline 1 & Walz et al. ${ }^{21)}$ & 58 & $\mathrm{M}$ & Moyamoya & $\mathrm{C} 4$ & endovascular & - & - & no change \\
\hline 2 & Gonzalez et al. ${ }^{3)}$ & 30 & M & NA & $\mathrm{T} 11$ & + & - & NA & excellent \\
\hline 3 & & 73 & M & NA & T6-7 & + & - & - & excellent \\
\hline 4 & & 54 & M & dissection & $\mathrm{T} 12$ & + & dissection & - & excellent \\
\hline 5 & & 69 & M & NA & NA & + & - & NA & excellent \\
\hline 6 & Massand et al. ${ }^{20)}$ & 30 & M & dissection & $\mathrm{T} 11$ & + & - & - & excellent \\
\hline 7 & & 69 & M & dissection & L1 & + & dissection & - & poor \\
\hline 8 & & 54 & M & dissection & $\mathrm{T} 12$ & + & dissection & - & excellent \\
\hline 9 & & 73 & M & NA & $\mathrm{T} 7$ & + & - & - & NA \\
\hline 10 & Berlis et al. ${ }^{1}$ & 62 & $\mathrm{~F}$ & dissection & T5 & + & - & - & excellent \\
\hline 11 & & 48 & M & $\begin{array}{l}\text { autoimmune } \\
\text { disease }\end{array}$ & $\mathrm{T} 12$ & - & - & - & no change \\
\hline 12 & & 69 & $\mathrm{~F}$ & dissection & L1 & - & - & + & excellent \\
\hline 13 & Yahiro et al. ${ }^{12)}$ & 71 & $\mathrm{~F}$ & pseudoaneurysm & $\mathrm{T} 4-5$ & + & pseudoaneurysm & - & no change \\
\hline 14 & Kawamura et al.5) & 42 & M & NA & $\mathrm{C} 1$ & + & - & - & excellent \\
\hline 15 & Rengachary et al. ${ }^{9)}$ & 50 & $\mathrm{~F}$ & $\begin{array}{l}\text { autoimmune } \\
\text { disease }\end{array}$ & $\mathrm{T} 12$ & + & $\begin{array}{l}\text { autoimmune } \\
\text { disease }\end{array}$ & - & no change \\
\hline 16 & Bahar et al. ${ }^{15)}$ & 40 & M & Behçet's disease & $\mathrm{C} 5-6$ & - & - & - & excellent \\
\hline 17 & Goto et al. ${ }^{4)}$ & 53 & M & true saccular & $\mathrm{C} 2$ & + & $\begin{array}{l}\text { true saccular } \\
\text { aneurysm }\end{array}$ & - & excellent \\
\hline 18 & Hino et al. ${ }^{18)}$ & 45 & $\mathrm{~F}$ & coarctation & C5-6 & - & - & - & no change \\
\hline 19 & Saunders et al. ${ }^{10)}$ & 48 & $\mathrm{~F}$ & FMD & $\mathrm{T} 1$ & + & + & - & excellent \\
\hline 20 & Smith et al. ${ }^{11)}$ & 29 & M & NA & $\mathrm{T} 12, \mathrm{~L} 1$ & + & - & - & no change \\
\hline 21 & Kito et al. ${ }^{19)}$ & 37 & $\mathrm{~F}$ & PXE & T9-10 & - & - & - & excellent \\
\hline 22 & Moore et al. ${ }^{8)}$ & 30 & $\mathrm{~F}$ & NA & $\mathrm{C} 1$ & + & - & - & no change \\
\hline 23 & Vincent ${ }^{13)}$ & 30 & $\mathrm{~F}$ & NA & $\mathrm{C} 2$ & + & - & - & no change \\
\hline 24 & Kormos et al. ${ }^{6}$ & 31 & $\mathrm{~F}$ & hemangioblastoma & $\mathrm{C} 1$ & + & false aneurysm & - & excellent \\
\hline 25 & Fody et al. ${ }^{17)}$ & 50 & $\mathrm{~F}$ & SLE & midthoracic & - & autopsy & + & death \\
\hline 26 & Garcia et al. ${ }^{24)}$ & 34 & $\mathrm{~F}$ & infection & T6 & - & $\begin{array}{l}\text { infectious, } \\
\text { autopsy }\end{array}$ & + & death \\
\hline 27 & Banna et al. ${ }^{16)}$ & 40 & M & coarctation & C6-7 & - & autopsy & - & death \\
\hline 28 & Our case & 59 & $\mathrm{~F}$ & infection & $\mathrm{C} 5$ & + & infectious & + & death \\
\hline
\end{tabular}

FMD: fibromuscular hyperplesia, SLE: systemic lupus erythematosus, PXE: pseudoxanthoma elasticum, NA: date not available.

elasticum, and fibromuscular hyperplesia. ${ }^{1,3,6,10,15-21)}$ Reported cases of SAH caused by solitary spinal aneurysms and the underlying conditions are summarized in Table 1 . There were 28 cases, 15 men and 13 women, with age ranging from 30 years to 73 years (average 49.2 years). Location of the aneurysms was cervical in 10, thoracic in 15, and lumbar in 11 patients. Surgical interventions including endovascular procedures were performed in 20 cases, and histological examination was performed in 12 cases including autopsy cases. The outcome was excellent in 12 , poor or death in 5 , and fair with stabilized status in 8 cases. Neurological deterioration during the course of treatment was described in 4 cases. Notably, two of these four cases were of mycotic aneurysms with rebleeding. ${ }^{24)}$ Risks of rebleeding may be high with the spinal mycotic aneurysms, as has been known with the intracranial mycotic aneurysms. ${ }^{25)}$ On the other hand, accurate diagnosis of mycotic aneurysms may be difficult when it occurs in the spinal region. Intracranial mycotic aneurysms most commonly affect peripheral arteries, and the demography is different from the common saccular aneurysms. Spinal aneurysms are themselves rare, and location seems to be of little help in identifying the mycotic nature. Therefore, it may be judicious to conduct surgical exploration when seeing a solitary spinal aneurysm causing SAH. 


\section{Conflicts of Interest Disclosure}

The authors report no conflict of interest concerning the materials and methods used in this study or the findings specified in this article. All authors who are members of The Japan Neurosurgical Society (JNS) have registered online Self-reported COI Disclosure Statement Forms through the website for JNS members.

\section{References}

1) Berlis A, Scheufler KM, Schmahl C, Rauer S, Götz F, Schumacher M: Solitary spinal artery aneurysms as a rare source of spinal subarachnoid hemorrhage: potential etiology and treatment strategy. AJNR Am J Neuroradiol 26: 405-410, 2005

2) Chen CC, Bellon RJ, Ogilvy CS, Putman CM: Aneurysms of the lateral spinal artery: report of two cases. Neurosurgery 48: 949-953; discussion 953-954, 2001

3) Gonzalez LF, Zabramski JM, Tabrizi P, Wallace RC, Massand MG, Spetzler RF: Spontaneous spinal subarachnoid hemorrhage secondary to spinal aneurysms: diagnosis and treatment paradigm. Neurosurgery 57: 1127-1131; discussion 1127-1131, 2005

4) Goto Y, Kamijyo Y, Yonekawa Y, Kikuchi H: Ruptured aneurysm of the posterior spinal artery of the upper cervical spinal cord: case report. Neurosurgery 22: 558-560, 1988

5) Kawamura S, Yoshida T, Nonoyama Y, Yamada M, Suzuki A, Yasui N: Ruptured anterior spinal artery aneurysm: a case report. Surg Neurol 51: 608-612, 1999

6) Kormos RL, Tucker WS, Bilbao JM, Gladstone RM, Bass AG: Subarachnoid hemorrhage due to a spinal cord hemangioblastoma: case report. Neurosurgery 6: 657-660, 1980

7) Miyamoto S, Kikuchi H, Karasawa J, Ikota T, Nagata I: Spinal cord arteriovenous malformations associated with spinal aneurysms. Neurosurgery 13: 577-580, 1983

8) Moore DW, Hunt WE, Zimmerman JE: Ruptured anterior spinal artery aneurysm: repair via a posterior approach. Neurosurgery 10 : 626-630, 1982

9) Rengachary SS, Duke DA, Tsai FY, Kragel PJ: Spinal arterial aneurysm: case report. Neurosurgery 33: 125-129; discussion 129-130, 1993

10) Saunders FW, Birchard D, Willmer J: Spinal artery aneurysm. Surg Neurol 27: 269-272, 1987

11) Smith BS, Penka CF, Erickson LS, Matsuo F: Subarachnoid hemor- rhage due to anterior spinal artery aneurysm. Neurosurgery 18: 217219, 1986

12) Yahiro T, Hirakawa K, Iwaasa $M$, Tsugu $H$, Fukushima $T$, Utsunomiya $\mathrm{H}$ : Pseudoaneurysm of the thoracic radiculomedullary artery with subarachnoid hemorrhage. J Neurosurg 100(3Suppl Spine): 312-315, 2004

13) Vincent FM: Anterior spinal artery aneurysm presenting as a subarachnoid hemorrhage. Stroke 12: 230-232, 1981

14) Herdt JR, Di Chiro G, Doppman JL: Combined arterial and arteriovenous aneurysms of the spinal cord. Radiology 99: 589-593, 1971

15) Bahar S, Coban O, Gürvit IH, Akman-Demir G, Gökyiğit A: Spontaneous dissection of the extracranial vertebral artery with spinal subarachnoid haemorrhage in a patient with Behçet's disease. Neuroradiology 35: 352-354, 1993

16) Banna MM, Rose PG, Pearce GW: Coarctation of the aorta as a cause of spinal subarachnoid hemorrhage. Case report. J Neurosurg 39: 761763,1973

17) Fody EP, Netsky MG, Mrak RE: Subarachnoid spinal hemorrhage in a case of systemic lupus erythematosus. Arch Neurol 37: 173-174, 1980

18) Hino $\mathrm{H}$, Maruyama $\mathrm{H}$, Inomata $\mathrm{H}$ : [A case of spinal artery aneurysm presenting transverse myelopathy associated with coarctation of the arota]. Rinsho Shinkeigaku 29: 1009-1012, 1989 (Japanese)

19) Kito K, Kobayashi N, Mori N, Kohno H: Ruptured aneurysm of the anterior spinal artery associated with pseudoxanthoma elasticum. Case report. J Neurosurg 58: 126-128, 1983

20) Massand MG, Wallace RC, Gonzalez LF, Zabramski JM, Spetzler RF: Subarachnoid hemorrhage due to isolated spinal artery aneurysm in four patients. AJNR Am J Neuroradiol 26: 2415-2419, 2005

21) Walz DM, Woldenberg RF, Setton A: Pseudoaneurysm of the anterior spinal artery in a patient with Moyamoya: an unusual cause of subarachnoid hemorrhage. AJNR Am J Neuroradiol 27: 1576-1578, 2006

22) Kim P, Murata H, Kurokawa R, Takaishi Y, Asakuno K, Kawamoto T: Myoarchitectonic spinolaminoplasty: efficacy in reconstituting the cervical musculature and preserving biomechanical function. $J$ Neurosurg Spine 7: 293-304, 2007

23) Biondi A, Merland JJ, Hodes JE, Pruvo JP, Reizine D: Aneurysms of spinal arteries associated with intramedullary arteriovenous malformations. I. Angiographic and clinical aspects. AJNR Am J Neuroradiol 13: 913-922, 1992

24) Garcia CA, Dulcey S, Dulcey J: Ruptured aneurysm of the spinal artery of Adamkiewicz during pregnancy. Neurology 29: 394-398, 1979

25) Frazee JG, Cahan LD, Winter J: Bacterial intracranial aneurysms. $J$ Neurosurg 53: 633-641, 1980

Corresponding author:

Homare Nakamura, MD, Department of Neurosurgery, St. Marianna University School of Medicine, Yokohama City Seibu Hospital, 1197-1 Yasashi-cho, Asahi-ku, Yokohama, Kanagawa 241-0811, Japan.

$\triangle$ homare@marianna-u.ac.jp 